\title{
Reforma y contrarreforma de la enseñanza primaria durante la II República Española y el ascenso del Fascismo (1932-1943)1
}

\author{
Justo Cuño Bonito ${ }^{2}$ \\ Universidad Pablo de Olavide (España) \\ Grupo de Investigación ILAC \\ jcubon@gmail.com
}

Recepción: 09/10/2012

Evaluación: 31/05/2013

Aceptación: 28/06/2013

Artículo de Reflexión

DOI: http:/ / dx.doi.org/ 10.9757/ Rhela. 21.03

\section{RESUMEN}

En el tradicional enfrentamiento entre las dos Españas, una vez más, la más rancia y conservadora España tradicionalista acabó imponiendo su dominio sobre la España librepensadora. El intento de reforma integral del sistema educativo como paso imprescindible para una profunda transformación social, puesto en marcha por la Segunda República española, acabó fracasando por la reticencia de la iglesia y élites más conservadoras, ante cualquier modificación social de calado. Quizá, como fruto de este perenne conflicto, el sistema educativo actual carece de un modelo estable y consensuable y constantemente se remodela por mor, no de su eficiencia, evolución metodológica y conceptual y amplitud de miras, sino por las vicisitudes ideológicas de los dos grandes partidos o por el afán de pervivencia y perpetuidad del ministerio del ramo de turno.

Palabras clave: Revista Historia de la Educación Latinoamericana, II República Española, Constitución Española de 1931, sistema educativo, educación primaria, maestras y maestros, plan profesional, represión franquista, concordato, nueva reforma educativa.

1 Resultado del proyecto de investigación: La Universidad en la capacitación de Maestras Rurales en Colombia y Guatemala, código SGI: 1034, que se desarrolló en protocolo con las Universidades: Pablo de Olavide de Sevilla-España, la Universidad San Carlos, Guatemala y la Universidad Pedagógica y Tecnológica de Colombia con el grupo de investigación Historia y Prospectiva de la Universidad Latinoamericana HISULA.

2 Doctor en Historia de América por la Universidad Pablo de Olavide de Sevilla-España. Licenciado en Filosofía y letras por la Universidad de Alcalá de Henares-Madrid. Director y Coordinador del Colegio de América, Centro de Estudios Avanzados para América Latina y el Caribe de la Universidad Pablo de Olavide de Sevilla-España. Investigador principal del proyecto La Universidad en la capacitación de Maestras Rurales en Colombia y Guatemala. Investigador del grupo Ilustración en América Colonial-ILAC (UPTC). 
Reform and counter-reform of primary education during the Second Spanish Republic and the rise of the fascism (1932-1943)
Reforma e contrarreforma do ensino primário durante a II República Espanhola e a ascensão do Fascismo (1932-1943)

\section{ABSTRACT}

In the traditional clash between The two Spains, the most mellow and conservative traditionalist Spain ended up by imposing its domain over the freethinker Spain once again. The attempt to have a comprehensive reform of the educational system as an essential step for a deep social transformation, launched by the Second Spanish Republic, just failing by the reluctance of the church and more conservative elites, before any modification of social setting. Perhaps, as a result of this perennial conflict, the current education system lacks a stable and constantly model redesign pormor [AT1], not its efficiency, conceptual and methodological developments and breadth of view, but ideological by the difficulties of the two major parties or by the desire for survival and perpetuity of the ministry of that epoch.

Key words: Journal History of the Latin-American Education, the Ind Spanish Republic, Spanish Constitution of 1931, educational system, primary education, teachers, professional plan, pro-Franco repression, concordat, new educational reform.
RESUMO

No tradicional conflito entre as duas Espanhas, uma vez mais, a mais rançosa e conservadora Espanha tradicionalista acabou impondo seu domínio sobra a Espanha livre-pensadora. O objetivo de reforma integral do sistema educativo como passo imprescindível para uma profunda transformação social iniciada pela Segunda República espanhola acabou fracassando pela resistência da igreja e das elites mais conservadoras diante de qualquer mudança social de fundo. Talvez como fruto deste eterno conflito, o sistema educativo atual necessita de um modelo estável e consensual, e que constantemente se remodela por causa, não de sua eficiência, por evolução metodológica e conceitual e ampliação da visão, mas pelas vicissitudes ideológicas dos grandes partidos ou pelo desejo de sobrevivência e perpetuação do ministério do ramo de turno.

Palavras-Chave: Revista História da Educação
Latino-americana II República Espanhola,
Constituição Espanhola de 1931, sistema educativo,
educação primária, professoras e professores, plano
profissional, repressão franquista, concordata, nova
reforma educativa.

Palavras-Chave: Revista História da Educação Constituição Espanhola de 1931, sistema educativo, educação primária, professoras e professores, plano reforma educativa.

\section{INTRODUCCIÓN}

Hacia una nueva sociedad por medio de la reforma de la educación básica, el artículo plantea cómo el nuevo sistema de gobierno republicano en España intentó edificar una nueva sociedad por medio de la reformulación integral del modelo educativo básico y cómo la más rancia élite tradicional (política y religiosa) bloqueó esta renovación de la estructura sociopolítica por medio del golpe de estado del 17 de julio 1936.

Entre los objetivos planteados se intentará demostrar cómo y por qué el gobierno republicano no inició esta reforma en la educación superior sino en aquella ineludible para cualquier renovación social: la educación básica, de 
la que reformuló el sistema de acceso, de organización, su estructura y, sobre todo, la metodología de formación de los docentes que debían implantar el nuevo modelo educativo.

La metodología empleada analiza numerosas fuentes primarias publicadas y algunas de las más recientes investigaciones sobre el periodo. Entre las conclusiones se plantea cómo el nuevo modelo progresó en un tiempo record y cómo, en un tiempo más breve aún, fue demolido por el viejo sistema tradicional que aún regía las mentalidades de la mayor parte de la élite sociopolítica. La iglesia, que había sido la mayor perjudicada por el cambio de paradigma, resultó ser la más beneficiada por el levantamiento fascista, al que apoyó sin fisuras y del que obtuvo, de nuevo, el control casi total sobre la educación básica. Los maestros republicanos, al contrario, se convirtieron en uno de los colectivos más represaliados durante la cruenta guerra civil.

\section{Hacia un nuevo modelo social por medio del cambio del modelo de educación básica}

La Constitución de la República Española, promulgada el 9 de diciembre de 1931 puso fin, por primera vez en la historia del constitucionalismo español, a la confesionalidad del Estado al proclamar en el artículo 3 "El Estado Español no tiene religión oficial". En el artículo 26 se definieron las confesiones religiosas como "asociaciones sometidas a una ley especial" y se prohibió que recibieran algún tipo de subvención por parte del Estado. Las órdenes religiosas con un voto de obediencia a una autoridad distinta a la legítima del Estado (el caso de los jesuitas) serían disueltas y sus bienes nacionalizados. El resto de órdenes quedarían sometidas a una ley que les prohibiría, entre otras cosas, ejercer la enseñanza. A ese respecto, el artículo 48 estructuraba la escuela laica y la unificada, quedando la actividad educativa de la iglesia limitada a "enseñar sus respectivas doctrinas en sus propios establecimientos" y siempre bajo la inspección del Estado. ${ }^{3}$

En los años 30, como ha indicado José María Maravall, ${ }^{4}$ el sistema educativo español se hallaba en condiciones muy precarias. El Estado tenía una presencia débil, subordinado a la actuación de la Iglesia católica en la

3 Joan Oliver Araújo, El Sistema Político de la Constitución Española del 31 (Islas Baleares: Universitat de les Illes Balears, 1991 ), 46 y ss.

4 José María Maravall, "Prólogo". En María Antonia Iglesias, Maestros de la República: Los otros Santos, los otros Mártires (Madrid: La Esfera de los Libros, 2006): 7 y ss. 
enseñanza. La desidia pública se manifestaba en varios aspectos: en los niveles primarios de la educación, en la discriminación que tenía lugar entre quienes podían cursar el bachillerato y quienes no tenían la posibilidad de estudiar tras la primaria y en la dejación de la enseñanza secundaria. Al respecto, Francisco Giner de los Ríos señaló: “De todos los problemas que interesan a la regeneración político-social de nuestro pueblo, no conozco uno solo tan menospreciado como el de la educación nacional". De esta forma, la Segunda República nació con un programa de reforma global del sistema educativo que incluía la construcción urgente de escuelas, la dignificación del maestro con un aumento sustancial de sus retribuciones, el establecimiento de un sistema unitario de tres ciclos, el fomento de una pedagogía activa y participativa, una concepción laica de la enseñanza.

Las medidas adoptadas se pusieron en marcha por medio de una serie de decretos gubernamentales: por medio del decreto de 29 de mayo de 1931 las misiones pedagógicas, quedaron "encargadas de difundir la cultura general, la orientación docente moderna y la educación ciudadana en aldeas, villas y lugares, con especial atención a los intereses espirituales de la población rural". Mediante el decreto de 13 de mayo de 1931, quedó suprimido el Plan Calleja de bachillerato y fue restablecido el Plan de estudios de 1903 que reformaba la enseñanza media. El decreto de 21 de mayo estableció la obligatoriedad de ostentar el título de maestro para la enseñanza primaria tanto privada como pública y el de licenciado para la enseñanza media. Además, el Gobierno acometió la empresa de mayor calado paraconsolidar la reforma educativa ideando una nueva ley de instrucción pública con el fin de edificar en España la escuela única, que había sido, desde hacía tiempo, el principal reclamo de sectores republicanos de un amplio espectro ideológico.

Mediante una batería de decretos urgentes se modificó la perspectiva que debía mantenerse en la nueva institución educativa: el reconocimiento de un Estado plural y con diferencias lingüísticas (aunque respetándose la lengua materna de los alumnos). Al frente del Consejo de Instrucción Pública que debía implantar las reformas, se nombró a Miguel de Unamuno. Por medio de otros decretos posteriores, se intentaron aligerar los plazos y procedimientos de colaboración entre el Estado y el municipio para la construcción de nuevas escuelas y, mediante el decreto de 27 de enero de 1932, se otorgaron a la Sección Pedagógica de la Facultad de Filosofía y Letras de la Universidad de Madrid las misiones de cultivar las ciencias de la educación y el desarrollo 
de los estudios superiores pedagógicos, de la formación del profesorado de segunda enseñanza y de Escuelas Normales y de la Inspección de Primera Enseñanza y de los directores de escuelas graduadas (Art. $1^{\circ}$ ).

Sin duda, la más favorecida con todas las reformas legislativas fue la enseñanza primaria. El decreto del 2 de diciembre de 1932 estableció una concepción más moderna e hizo del inspector un especialista técnico-pedagógico, un consejero y un orientador del maestro. En la enseñanza media, el decreto del 30 de diciembre del mismo año también reformó esta educación en el mismo sentido.

En el aspecto religioso, la legislación se enfrentó al problema derivado de la ley de Confesiones y Congregaciones Religiosas: se ordenó el cierre de esta enseñanza para el 1 de octubre de 1933, quedó exceptuada solo la enseñanza primaria cuya extinción fue efectiva el 1 de enero de 1934. De todo ello se encargó la recién creada Junta de Sustitución que debió reformar la enseñanza, los profesores y edificios religiosos por laicos. ${ }^{5}$

El Estado Republicano asumió la educación como uno de los objetivos fundamentales de su acción de gobierno, la instrucción pública debía estructurar una nueva sociedad a partir de una nueva escuela laica, mixta, científica, de calidad y de progreso. Los responsables educativos del Ministerio de Instrucción Pública y Bellas Artes concibieron la educación como un medio de liberación de las clases populares. ${ }^{6}$

Se proyectó la creación progresiva de 27000 escuelas, pero mientras los recintos educativos estaban listos, los ayuntamientos pusieron salas a disposición de la labor educativa del estado y las maestras, subvencionadas por los ayuntamientos, llegaron a acoger en sus propias casas a los escolares. ${ }^{7}$

Pero incluso antes que educar, la República tuvo que dar de comer a los niños y vestirlos. ${ }^{8}$ Había cantinas y roperos escolares, y cobraron fuerza las

5 La información sobre los decretos legislativos ha sido extraída de la Colección Legislativa de Instrucción Pública (año 1931), (Madrid: 1932), 207-211; Colección Legislativa de Instrucción Pública (año 1934), (Madrid), 551-559. Ver también la obra de Mariano Pérez Galá, "La enseñanza en la II República Española”. Cuadernos para el Diálogo (Madrid: 1975): 62-64.

6 Antonio Bustos Jiménez, “La Escuela Rural Española ante un contexto en transformación”, Revista de Educación350 (2011): 37.

7 Molero Pintado, Antonio. Historia de la Educación en España. IV. La Educación durante la Segunda República y la Guerra Civil (1931-1939) (Madrid: Ministerio de Educación y Ciencia, 1991), 56.

8 Carmen Morán, De la República (Madrid: El País, 2012). Consultado con fecha 06/06/2012 http://elpais.com/diario/2006/04/17/ educacion/1145224801_850215.html 
Colonias Escolares que ya antes había puesto en marcha Bartolomé Cossío. ${ }^{9}$ Los niños viajaban al mar o a la montaña. Hacían deporte, se divertían. Pero, sobre todo, comían. En quince días algunos ganaban hasta cuatro kilos de peso.

Hubo medidas urgentes que no podían esperar y que se adoptaron a golpe de decreto, hasta que fue aprobada la Constitución. Lo más revolucionario después de facilitar alimentación, fueron las Misiones Pedagógicas de cuyo patronato fue también presidente Cossío. El esfuerzo modernizador emprendido por la República encontró de inmediato la ayuda de los intelectuales: escritores, poetas, pedagogos... planificaron y desarrollaron una cultura ambulante que intentó llegar hasta los más remotos confines del abandonado territorio rural español. En destartaladas camionetas llegaron a las aldeas perdidas bibliotecas itinerantes, proyecciones cinematográficas, teatro, museos ambulantes. El 70\% de los hombres eran analfabetos; mucho más las mujeres. En aquellas Misiones Pedagógicas se embarcaron grandes poetas, afamados escritores y maestros con su corbata y maletín a los que los lugareños recogían en burro donde las camionetas ya no tenían acceso.

\section{El Plan Profesional}

Para mejorar la formación de los maestros y dignificar la profesión, el Ministerio de Instrucción Pública diseñó un completo Plan Profesional. En cuatro años, entre abril de 1931 y abril de 1935, el número de maestros nacionales pasó de 37500 a $50500 .^{10}$

El nuevo Plan, decretado el 29 de septiembre de 1931, sustituyó al obsoleto de 1914. En el preámbulo del decreto se indicó que:

Urgía crear escuelas, pero urgía más crear Maestros; urgía dotar a la Escuela de medios para que cumpliera la función social que le está encomendada; pero urgía más capacitar al Maestro para convertirlo en sacerdote de esta función; urgímelevar la jerarquía de la Escuela, pero urgía igualmente dar al Maestro de la nueva sociedad democrática la jerarquía que merece y merecerá haciéndole merecedor de ella. ${ }^{11}$

9 Francisco Canes Garrido, "Las Misiones Pedagógicas: Educación y Tiempo Libre en la Segunda República”, Revista Complutense de Educación 4 (1993): 24 y ss.

10 Colección Legislativa de Instrucción Pública (Año 1931- 1934), Madrid.

11 Carmen Fernández Rubio, La Escuela Normal Masculina de Oviedo y su Incidencia en la Formación de Maestros (1900-1940) (Oviedo: Servicio de Publicaciones de la Universidad de Oviedo, 1997), 55. 
"De ahora en adelante, quien elija la profesión de maestro, pudiendo seguir otros caminos, lo hará porque a ello le impulse la vocación", aseguró Rodolfo Llopis, director general de Primera Enseñanza entre 1931 y 1933. A las órdenes de Marcelino Domingo, ministro de Instrucción Pública, Llopis puso en marcha una ambiciosa reforma de la formación docente que pretendía alejar a los mediocres del Magisterio y dotar a la recién nacida República de la mejor generación de maestros que había conocido España. ${ }^{12} \mathrm{El}$ objetivo fue renovar completamente la escuela española, al dotar a los maestros de una formación contundente y específica. Completado el bachillerato, los aspirantes pasarían una exigente prueba de selección para entrar en las Escuelas Normales. "Ese era el cribado realmente duro, solo ingresaban unos 40 estudiantes en cada escuela provincial". Ingresaron 965 por ese método en un primer momento. Una vez dentro, los aspirantes -hombres y mujeres por primera vez juntos- pasarían tres años de formación más uno de prácticas, pagadas, en las escuelas. Los inspectores y los profesores de la Normal tutelaban el aprendizaje y componían los tribunales. Sin oposiciones, los estudiantes que pasaran con éxito esa etapa eran ya maestros funcionarios. El esfuerzo mayor se hizo en primaria, lo demás no se pudo concluir.

El plan de formación del profesorado fue el más completo y ambicioso que se había establecido en España para la formación del magisterio primario. ${ }^{13}$ Era frecuente oír en los ámbitos escolares, hasta los años setenta del pasado siglo, expresarse a los directores de los colegios, frente a la excelencia del trabajo y del saber de un maestro o una maestra con la siguiente frase: "Es del Plan Profesional". ${ }^{14}$ Los maestros formados en aquel plan estuvieron muy posicionados políticamente, $\mathrm{y}$ fueron progresistas y con un talante fuertemente reivindicativo. ${ }^{15}$

La normativa educativa aprobada en estos años reguló el bilingüismo al permitir que en las escuelas primarias se enseñase en lengua materna aunque fuese diferente del castellano, se suprimió la obligatoriedad de la enseñanza religiosa y se reguló la inspección de la primera y segunda enseñanza.

12 Carmen Morán. El Maestro de la II República que intuyó el Futuro (Madrid: El País, 2003). Consultado con fecha 06/06/2012 http://elpais.com/diario/2011/09/12/sociedad/1315778406_850215.html

13 Juan Antonio Lorenzo Vicente, "Perspectiva histórica de la formación de los maestros en España (1370-1990)", Revista Complutense de Educación 6,2 (1995): 223-229.

14 Manuel Santander Díaz, "La reforma en la formación de los Maestros de Enseñanza Primaria: El plan profesional de 1931". Revista Tavira 26 (2010): 57-103.

15 Carmen Morán. Represión contra los maestros en la Guerra Civil (Madrid: El País, 2003). Consultado con fecha 30/06/2012 http://elpais.com/diario/2003/01/27/educacion/1043622001_850215.html 
Fruto de ello fue la aparición de las primeras profesoras de bachillerato, inspectoras de educación y profesoras contratadas por la Universidad. Incluso muchas maestras, ayudadas económicamente por la Junta de Ampliación de Estudios, ${ }^{16}$ se desplazaron a otros países para conocer sus sistemas educativos. ${ }^{17}$

Las maestras republicanas buscaron un campo propio de actuación mediante la reivindicación de prácticas educativas innovadoras aplicables en los centros docentes. Desarrollaron su labor en todas las actividades educativas y culturales desplegadas por la República: Escuelas nocturnas para trabajadoras adultas, Misiones Pedagógicas, Bibliotecas Populares, colonias y cantinas escolares.

Estuvieron comprometidas políticamente, participaron en campañas políticas, iniciaron la enseñanza de temas antes prohibidos como el de la educación sexual e introdujeron un firme conocimiento laico tolerante y con respecto a todas las creencias.

\section{La Reacción}

Pero respecto a todas las reformas republicanas emprendidas, en el derechista "Diario de Málaga" un artículo del periodista Ossorio y Gallardo se preguntaba “¿Qué función tiene el Estado en la enseñanza?" e indicó que:

El recrudecimiento de la lucha entre el Vaticano y el fascismo vuelve a poner en primer plano el problema de la tutela espiritual de la infancia. El Estado-monstruo quiere a todo trance absorberla para formar una ciudadanía militarizada al servicio de un ideal político. La Iglesia vindica su derecho a modelar el espíritu, no para imperar en la tierra, sino para purificarse y salvarse en la vida ultraterrena. Los padres colocados entre las dos sugestiones, antes responden a su criterio personal que a los deberes de su función. Son, efectivamente, los padres quienes han de recabar el papel predominante (...) Después de los padres es legítimo que la iglesia ocupe lugar preferente en la tarea educativa porque el fundamento de las acciones humanas es una ley ética; y esta no tiene apoyo firme sino en la idea religiosa ${ }^{18}[\ldots]$.

16 Germán Gómez Orfanel, "La Junta de Ampliación de Estudios y su política de Pensiones en el Extranjero", Circunstancia. Año V, 14 (Septiembre 2007): 28-47.

17 María Cruz del Amo del Amo, "La Educación de las Mujeres en España: de la 'amiga' a la Universidad". CEE Participación Educativa, 11 julio (2009): 8-22

18 Ángel Ossorio y Gallardo, “¿De quién es el niño?”, Diario de Málaga, 9 de julio de 1931. 
Por el contrario, en el diario El Popular, periódico del Partido Republicano Radical-Socialista, ${ }^{19}$ se expuso que:

El pueblo sitúa sus afanes de redención en la escuela. Su convencimiento le dice que la regeneración social y política, la capacitación para el ejercicio real y consciente de su soberanía no puede venir por otro camino [...] el tema cultural no es, pues, emblema de una mayoría simbólica ni de una escogida minoría, es por el contrario un vehemente anhelo nacional de la totalidad [...]. Por lo tanto, la escuela es un atributo indeclinable del poder central. Y siendo así, no puede delegarse.

Pero la dictadura exterminó aquella escuela. Los nacionales se encargaron de "aniquilar la semilla de Caín", como proclamó el entonces obispo de Salamanca, Pla i Deniel. La depuración durante y después de la guerra dejó unos 15000 expulsados y unos 6000 sancionados. Lo menos grave es que estuvieron 18 meses sin cobrar. ${ }^{20}$

En los primeros días de la sublevación, un periódico de Sevilla publicó un artículo con el significativo título de "A las cabezas", donde un tal F. Contreras decía:

No es justo que se degüelle al rebaño y se salven los pastores. Ni un minuto más pueden seguir impunes los masones, los políticos, los periodistas, los maestros, los catedráticos, los publicistas, la escuela, la cátedra, la prensa, la revista, el libro y la tribuna, que fueron la premisa y la causa de las conclusiones y efectos que lamentamos. ${ }^{21}$

Como ejemplo de la represión cometida contra las maestras y los maestros de la II República Española, hay innumerables ejemplos. Quizá uno de los más significativos sea el caso de Severiano Núñez García. La madrugada del 16 de agosto de 1936 sacaron a Severiano Núñez García de la cárcel de Plasencia (Cáceres) camino de la tapia del cementerio. Un tiro, o quizá más, acabaron con la vida del maestro de Jaraíz de la Vera (Cáceres). No había delito. Su viuda no volvió jamás a pronunciar una palabra. Severiano había nacido 41 años antes en otro pueblo de la provincia, Barrado. Su historia, como sus huesos, se pudría en silencio hasta que un sobrino suyo, maestro

19 E. Ruiz de Silva, "Sobre la Escuela Unificada y Regionalismo", El Popular, 5 de agosto de 1931.

20 Jaime Botey Vallés, "Memoria histórica, asesinatos y beatificación", El Sueño Igualitario. Memoria en campo abierto 48 (2007): Págs. 9 - 17

21 Josep Fontana, "El Holocausto Español". Publico.es, 2011. Consultado con fecha 18/06/2012 http://blogs.publico.es/ dominiopublico/3385/el-holocausto-espanol/ 
jubilado, hijo, nieto y hermano de maestros, ha podido rescatarla. Como último testimonio de la vida del profesor, quedó la carta escrita a su esposa poco antes de su asesinato:

Querida Julia, como supongo que cuando vengas no tendré ánimo para poder hablarte con la suficiente serenidad, te escribo esta carta, que no sé si llegará a tus manos, para decirte solamente una cosa: yo soy inocente. En estos momentos solemnes en que no se miente porque la mentira es inútil yo deseo y quiero llevar a tu ánimo, al de la familia, la idea que dejo expresada y en la convicción de conseguirlo muero tranquilo. ${ }^{22}$

El 17 de julio de 1936, día del alzamiento fascista, sorprendió a los maestros españoles de vacaciones. Entonces no sabían que aquella fecha daba inicio a la más penosa etapa que iban a vivir los docentes en España. Tanto, que algunos historiadores no dudan cuando dicen que fue el colectivo más castigado por la represión franquista. Se les consideró responsables de haber inoculado en la sociedad y en las mentes juveniles el virus republicano. Además, se intentó atajar de raíz la posibilidad de que la moral nacionalcatolicista, que el régimen fascista quería imponer, tuviera cualquier otro contrincante y, al tiempo, se buscó aplicar un castigo ejemplarizante a los intelectuales en general que quitara las ganas a cualquier otro de repetir aquel modelo de vida que representaban los maestros republicanos. ${ }^{23}$

\section{La Represión}

Y lo consiguieron. El miedo atenazó las escuelas y las familias de los maestros. Los que no murieron fusilados tras el levantamiento militar pasaron en su exilio interior la más terrible purga profesional. El historiador Morente Valero ha contado hasta 60000 maestros depurados. Hubo denuncias privadas de vecinos, en las que se acusaba al maestro de haber tocado el piano en un baile público, por ejemplo. En un pueblo de Lugo, el alcalde se deshizo del maestro, que no era precisamente de izquierdas, porque en su lugar estaría mejor una señorita católica, de familia decente, como Dios manda. El alcalde adjuntaba en su informe esta posdata: "El hecho de que esta señorita sea mi hija no es el motivo de la destitución del maestro".

22 Carmen Morán. “Represión contra los maestros en la Guerra Civil”. El País, 2003. Consultado con fecha 30/06/2012 http://elpais. com/diario/2003/01/27/educacion/1043622001_850215.html

23 Francisco Morente Valero, "La Depuración Franquista del Magisterio Público: Un estado de la cuestión". Hispania: Revista española de historia 208 (2001): 661 - 688 
Ante tanto asesinado y depurado y pese a los puestos adjudicados a familiares, muchos curas y algunos militares, hasta 2500 alféreces, se hicieron cargo de la educación después de la guerra.

En 1937, José Pemartín, jefe fascista del Servicio de Enseñanza Superior y Media, declaró que "Tal vez un 75 por ciento del personal oficial enseñante ha traicionado -unos abiertamente, otros solapadamente, que son los más peligrosos- la causa nacional [...]. Una depuración inevitable va a disminuir considerablemente, sin duda, la cantidad de personas de la enseñanza oficial".$^{24}$ En nueve provincias fueron ejecutados en torno a 250 maestros. Y 54 institutos públicos de enseñanza secundaria creados por la República fueron cerrados. En torno a un 25 por ciento de los maestros sufrieron algún tipo de represión y un 10 por ciento fue inhabilitados de por vida. En Euskadi y Cataluña, todos los maestros de la enseñanza pública fueron dados de baja y tuvieron que solicitar su readmisión por medio de un costoso proceso. ${ }^{25}$

La Iglesia desempeñó un papel fundamental en la represión y la depuración del magisterio. Por la relevancia de la Iglesia en la insurrección militar y en el nuevo régimen, el catolicismo formó parte de las estrategias para sobrevivir y para hacer frente al miedo. En otro de los testimonios fundamentales para comprender este período, Hilda Farfante, hija de los directores de las escuelas primarias de Cangas de Narcea, hija de Balbina y Ceferino, asesinados en septiembre de 1936, ambos fusilados, relató la historia de su represión: ${ }^{26}$

Yo iba a la iglesia y lloraba y todo el mundo creía que lloraba por mis pecados [...]. Pero yo aquello lo asumía de otra manera porque era una niña, lo asumía como que mis padres eran culpables [...]. Yo me acuerdo de levantarme a las siete de la mañana antes de ir a la escuela, para ir a misa a comulgar y a confesar, todos los días [...]. Recuerdo una costumbre que decía que si el Día de los Difuntos entrabas a la iglesia y rezabas siete padrenuestros y salías a la calle, y volvías a entrar y a rezar, cada vez sacabas un alma del purgatorio... Yo entraba y salía setenta veces, era la que más entraba y salía. ${ }^{27}$

24 Josep Fontana, "La Caza del Maestro". El País, 2006. Consultado con fecha 12/07/2012 http://elpais.com/diario/2006/08/10/ opinion/1155160805_850215.html

25 José María Maravall, "Prólogo".

26 María Antonia Iglesias, Maestros de la República: Los otros Santos, los otros Mártires (Madrid: La Esfera de los Libros, 2006), 47 y ss.

27 Herminio Lafoz Rabaza, Aniquilar la semilla de Caín. La represión del magisterio republicano, (Zaragoza: Instituto de Ciencias de la Educación Universidad de Zaragoza, 2007), 41 y ss. 
A su muerte, el hijo de un compañero de Hilda, relató lo que ella le había contado del asesinato de sus padres:

"Hilda, con 5 años, veraneaba con sus padres en Besullo; era la mediana de tres hermanas y sus padres ejercían siempre juntos. Era un 8 de septiembre y la madre tenía la responsabilidad de dejar Besullo y desplazarse a Cangas. Había que abrir la escuela. La guerra llevaba ya unas semanas de su propio curso, pero ella era la directora y como funcionaria de la República tenía la obligación de personarse y reanudar las clases; en principio, todo maestro lo piensa, la guerra no la hacen los niños. La mataron de un tiro en la nuca junto a los árboles en lo alto de Moal, a unos kilómetros de la escuela, junto a otras tres maestras como ella. Se llamaba Balbina Gayo Gutiérrez y tenía 34 años. Su marido no supo nada y pasó dos días pensando qué debía hacer. Cuenta Hilda que Alejandro Casona -otro maestro de escuela, hoy olvidado pero famoso entonces como autor de una obra teatral que sacaba a la derecha de sus casillas, Nuestra Natacha, que hoy nos haría sonreir por su candorinició desde Besullo, que también era su pueblo, el peregrinaje hacia el exilio, y recomendó a su padre que marchara con él. Tenía, pues, tres opciones. Quedarse con sus hijas y esperar, marchar con Alejandro Casona o ir a la búsqueda de su mujer. Si nunca se había separado de ella, no iba a hacerlo ahora. Escogió lo último. Le detuvieron, le ataron las manos atrás y le aplicaron la ley de fugas; lo mataron por la espalda en Bimeda, al otro lado de la Sierra de Pando, donde habían dado muerte a su mujer dos días antes. Se llamaba Ceferino Farfante Rodríguez y tenía 33 años".

Arturo Sanmartín Suñer, inspector de primera enseñanza en Palencia, fue asesinado junto a su esposa en los primeros días de julio de 1936. La prensa local dio cuenta de los horrores cometidos por los fascistas en Palencia: Más de quinientas personas fusiladas. La esposa del administrador de la prisión de Palencia, que por gestiones de la Embajada argentina pudo salir de dicha capital el 4 de febrero, dio cuenta de algunos datos relacionados con los hechos ocurridos a partir de la sublevación en aquella provincia. Entre ellos, relató el fusilamiento del coronel del regimiento de Caballería, que se había negado a sublevarse. Entre los elementos de izquierda fusilados, figuró el ex diputado a Cortes Mateo Peñalva, el presidente de la Diputación, Casallé; el secretario, Micó; varios maestros de la FETE y viejos militantes socialistas. El inspector de Primera enseñanza, San Martín, se escapó, de momento, a la persecución, escondiéndose bajo una plataforma de una escuela regentada por una maestra llamada Ubaldina. Encontrado después, fue paseado en un 
camión por la calle Mayor y más tarde lo fusilaron. Doña Ubaldina corrió la misma suerte y la esposa del inspector, maestra y propagandista socialista, fue encontrada muerta, mordida por los perros y con evidentes señales de haber sido ultrajada. La mayor parte de maestros y maestras de izquierda, indicaba la prensa, han sido fusilados y en las escuelas dan clase los curas. Se afirmó que eran más de quinientas las personas fusiladas, y en una sola tarde lo fueron cuarenta jóvenes socialistas. El clero se distingue por su crudeza de lenguaje y por los insultos que dirige a las mujeres y a los niños que han quedado sin el jefe de la familia. ${ }^{28}$

Las maestras, si cabe, fueron un grupo atacado aún con más fruición por los golpistas, de manera que se ejerció sobre ellas una represión con un carácter aún más represivo y ejemplarizante en su doble papel de enseñantes y mujeres. Las Comisiones Depuradoras franquistas, por las que tuvo que pasar todo el colectivo docente, "veían más grave que las maestras tuvieran ideas de izquierdas que las tuvieran los maestros". Porque feo y escandaloso, indicaron, es que un maestro con sus ideas "convierta la escuela en un semillero de comunistas; pero en una maestra sube de punto lo pernicioso de tales escándalos", señaló un miembro de aquellas comisiones. Las maestras acusadas de pertenecer a la federación de Enseñanza de UGT, la FETE, fueron calificadas directamente como "un caso perdido". "Llega a ser repulsiva la conducta de esa maestra, de veintisiete años de edad, en plena juventud ya pervertida", se expuso en la Comisión de Toledo sobre alguna docente. El régimen vio en ellas la incalculable traición de haber abandonado "su condición femenina y haberse distanciado de su papel de esposa y madre". Las hubo fusiladas o en términos de la época "paseadas", incluso ejecutadas al poco de iniciarse la guerra. Otras muchas debieron exiliarse normalmente a Hispanoamérica, donde ejercieron como maestras contribuyendo a la modernización de la educación en estos países, aunque normalmente se dedicaron a otros trabajos. ${ }^{29}$

El nacionalcatolicismo aniquiló la libertad de pensamiento, la tradición humanista y, sobre todo, a los maestros que habían desarrollado el mayor esfuerzo en la historia de España por renovar la enseñanza pública. La destrucción afectó también a las familias de los maestros y de las maestras

28 Herminio Lafoz Rabaza, Aniquilar la semilla de Caín. La represión del magisterio republicano, 58.

29 Carmen Morán. "Maestras Republicanas: la doble depuración”. El País, 2012. Consultado con fecha 18/07/2012 http://blogs.elpais. com/mujeres/2012/05/maestras-republicanas-la-doble-depuraci\%C3\%B3n.html 
republicanas y el adoctrinamiento y el miedo anularon cualquier atisbo de libertad de pensamiento. En el catecismo del padre Ripalda se preguntaba: “¿Hay otras libertades perniciosas? Sí señor, la libertad de enseñanza, la libertad de propaganda y de reunión. ¿Por qué son perniciosas esas libertades? Porque sirven para enseñar el error y propagar el vicio". En 1943, cuatro años después de finalizada la guerra civil, el ministro de Educación, José Ibáñez Martín, declaró ante las Cortes que:

\section{[...] lo verdaderamente importante desde el punto de vista político es arrancar de la docencia y de la creación científica la neutralidad ideoló- gica y desterrar el laicismo, para formar una nueva juventud, poseída de aquel principio agustiniano de que mucha ciencia no acerca al Ser Supremo. ${ }^{30}$}

El concordato de 1953 entre el Estado español y el Vaticano confirmó el monopolio católico sobre la educación española. El Estado aseguraba la enseñanza de la religión católica como parte obligatoria de los planes de estudio en todos los centros educativos del país, de cualquier clase y nivel, así como la conformidad de todas las enseñanzas con los principios de la Iglesia católica. ${ }^{31}$

\section{CONCLUSIÓN}

De las dos Españas acabó imponiéndose la tradicional, la reaccionaria, la antiliberal y ultraconservadora. Cualquier opción al librepensamiento quedó cortada de raíz, exterminados sus artífices, sus impulsores, sus forjadores y sus desarrolladores. Quedó establecida una pesada pátina sobre el pensamiento de la sociedad española que aún trata, infructuosamente de superar. Aún el sistema educativo es uno de los grandes escenarios de una batalla ideológica que impide su desarrollo y consolidación. Cada partido presenta sus reformas oportunistas y transitorias y las instituciones educativas se adaptan, readaptan, implantan y derogan las normativas que surgen de los planes personalistas de ministros sin vinculación, en la mayor parte de los casos, con el ámbito educativo.

30 Ángel Luis Abós Santabárbara, La historia que nos enseñaron: 1937-1975 (Madrid: Foca, ediciones y distribuciones generales, S.L., 2003), 23 y ss.

31 Rafael Gómez Pérez, El Franquismo y la Iglesia, (Madrid: Rialp, 1986), 51. 
Aún la iglesia y la derecha más conservadora fijan su objetivo en el control de la sociedad por medio de una educación ultramontana y pacata.

En 2012 el viernes 21 de septiembre el Consejo de Ministros de España aprobó el llamado Proyecto de ley orgánica para la mejora de la calidad educativa que, en la práctica, supone una modificación de la actual Ley Orgánica de Educación (LOE).

La propuesta inicial mantiene la estructura de la anterior ley (confesional y aprobada por el partido socialista), respecto a los temas confesionales: el régimen de conciertos y la religión en la escuela quedaron intactos. Se mantuvieron, por ejemplo, las disposiciones adicional segunda y tercera, que "potenciaba la religión en la escuela pública y otorgaba relevancia profesional al papel de las personas designadas por obispados" y deja de forma idéntica "todo lo que afecta a los conciertos con los centros privados". ${ }^{32}$

En los planes de estudio eliminaron la asignatura de Ética Cívica de $4^{\circ}$ de la Educación Secundaria Obligatoria, es decir la única asignatura que en Secundaria servía para enseñar la reflexión ética sin moral religiosa. También desaparece la asignatura Cultura Clásica de $3^{\circ} \mathrm{ESO}$, para perder el referente grecolatino de nuestra cultura y que solo quede el religioso (cristiano). Además, vulnerando el artículo 14 de la Constitución y frente a una reciente sentencia del Tribunal Supremo, se propone que se subvencionen centros religiosos que segreguen por sexos.

El modelo no es nada novedoso, pero resultó muy efectivo durante 40 años: años en que el fascismo arruinó las esperanzas de renovación social emprendidas por la escuela pública republicana y enclaustró nuevamente la libertad de pensamiento.

\section{FUENTES}

Boletín Oficial del Estado: La Depuración, 6 de Enero de 1940, No. 6, España. Colección Legislativa de Instrucción Pública (Año 1931-1934), Madrid.

32 Francisco Delgado, Nueva ley educación. Algunas primeras consideraciones (Madrid: El Observatorio de la Laicidad, 2012). Consultado con fecha 31/10/2012 http://www.laicismo.org/detalle.php?pk=17029 (septiembre, 2012). 


\section{REFERENCIAS}

Abós Santabárbara, Ángel Luis. La historia que nos enseñaron: 1937-1975. Madrid: Foca, ediciones y distribuciones generales, S.L., 2003.

Araújo Joan Oliver. El Sistema Político de la Constitución Española del 31. Islas Baleares: Universitat de les Illes Balears, 1991.

Boza Puerta, M. y M. A. Sánchez Herrador, "Las Bibliotecas en las Misiones Pedagógicas". Boletín de la Asociación Andaluza de Bibliotecarios74 (2004): 41-51

Botey Vallés, Jaime. "Memoria histórica, asesinatos y beatificación”. El Sueño Igualitario. Memoria en campo abierto 48 (2007): 9-17

Bustos Jiménez, Antonio. “La Escuela Rural Española ante un contexto en transformación". Revista de Educación 350 (2011): 449-461

Canes Garrido, Francisco. “Las Misiones Pedagógicas: Educación y Tiempo Libre en la Segunda República". Revista Complutense de Educación 4 (1993): 147-168

Carreño, Myriam. Teorías e Instituciones Contemporáneas de Educación. Madrid: Síntesis, 2000.

Corchón Álvarez, Edualdo. Escuela Rural: Pasado, Presente, Futuro. Madrid: Oikos-Tau, 2010.

De Fuelles Benítez, Manuel. Educación e Ideología en la España Contemporánea (17671975). Barcelona: Politeia, 1980.

Del Amo del Amo, María Cruz. "La Educación de las Mujeres en España: de la "amiga" a la Universidad" CEE Participación Educativa (2009): 8-22

Delgado, Francisco. Nueva ley educación. Algunas primeras consideraciones. Madrid: El Observatorio de la Laicidad, 2012. Consultado con fecha 31/10/2012 http:/ / www.laicismo.org/ detalle.php?pk=17029

Díez Fuentes, José María. “República y Primer Franquismo: La Mujer Española entre el esplendor y la miseria 1930-1950". Alternativas. Cuadernos de Trabajo Social 3 (1995): 23-40

Escolano Benito, Agustín. La Educación en la España Contemporánea: Políticas Educativas, Escolarización y Culturas Pedagógicas. Madrid: Biblioteca Nueva, 2002.

Fernández Rubio Carmen. La Escuela Normal Masculina de Oviedo y su Incidencia en la Formación de Maestros (1900-1940). Oviedo: Servicio de Publicaciones de la Universidad de Oviedo, 1997. 
Fontana, Josep. La Caza del Maestro. Madrid: El País, 2006. Consultado con fecha 12 / 07 / 2012 http: / / elpais.com/diario/2006/08/10/opinion/1155160805_850215.html

Lafoz Rabaza, Herminio. Aniquilar la semilla de Caín. La represión del magisterio republicano. Zaragoza: Instituto de Ciencias de la Educación Universidad de Zaragoza, 2007.

Maravall José María. "Prólogo". En Iglesias, Maestros de la República: Los otros Santos, los otros Mártires por María Antonia 10-25. Madrid: La Esfera de los Libros, 2006.

Martínez-Montalvo, Esperanza. “Política Bibliotecaria en la Guerra Civil Española (19361939): La Zona Nacional." Journal of Spanish Research on Information Science. I (2000): Vol. I, num. jan-june.

Mayordomo, Joaquín. “Una Maestra del 34”. En Reportaje: La Escuela de la II República. El País. 17 de abril de 2006. Consultado con fecha 06/06/2012 http:/ / www.elpais.com/articulo/educacion/maestra/34/Elpedupor/20060417elpepiedu_3/Tes

Molero Pintado, Antonio. Historia de la Educación en España. IV. La Educación durante la Segunda República y la Guerra Civil (1931-1939). Madrid: Ministerio de Educación y Ciencia, (1991).

Morán, Carmen. "Represión contra los maestros en la Guerra Civil". El País, 2003. Consultado con fecha 30/06/2012http://elpais.com/diario/2003/01/27/educacion /1043622001_850215.html

Morán, Carmen. "Maestras Republicanas: la doble depuración". El País, 2012. Consultado con fecha 18/07/2012 http:/ / blogs.elpais.com/mujeres/2012/05/maestras-republicanas-la-doble-depuraci\%C3\%B3n.html

Moreno Bresó, Francisca. Escuela y República: Cuaderno de una Maestra Rural, Documenta. Ciudad Real: Centro De Estudios De La Universidad De Castilla-La Mancha, 2009.

Morente Valero, Francisco. “La Depuración Franquista del Magisterio Público: Un estado de la cuestión", Hispania: Revista española de historia 208 (2001):661-688

Pérez Galán, Mariano. La Enseñanza en la Segunda República Española. Madrid: Editorial Edicusa, 1975.

Puelles Benítez, Manuel. Educación e Ideología en la España Contemporánea. Barcelona: Labor, 1991.

San Román, Sonsoles. Las Primeras Maestras. Los Orígenes del Proceso se feminización docente en España. Barcelona: Ariel, 1998.

Sánchez Anido, José. "Cuestiones de Enseñanza Doméstico-Agrícola”, La Escuela Moderna, 1 de Noviembre (1934): 510-519 
Silva, Angélica. "La Maestra Rural en la Posrevolución”. Céfiro: Enlace Hispano-Cultural y Literario Vol.7 No 1-2 (2000).

VV.AA., Las Misiones Pedagógicas (1931-1936). Madrid: CSIC-Residencia de Estudiantes, 2006. Consultado el 16/06/2012 http:/ / www.residencia.csic.es/misiones/presentacion/ inicio.htm

Zamora, Olegario Negrín Fajardo, Carmen de la Guardia Herrero y María del Mar del Pozo Andrés. Las Maestras de la República. Madrid: Los Libros de la Catarata, 2012.

Cuño Bonito, Justo. "Reforma y Contrarreforma de la enseñanza primaria durante la II República Española y el ascenso del Fascismo (1932 - 1943)". Revista Historia de la Educación Latinoamericana. Vol. 15 No, 21, (2013): 89 - 106. 